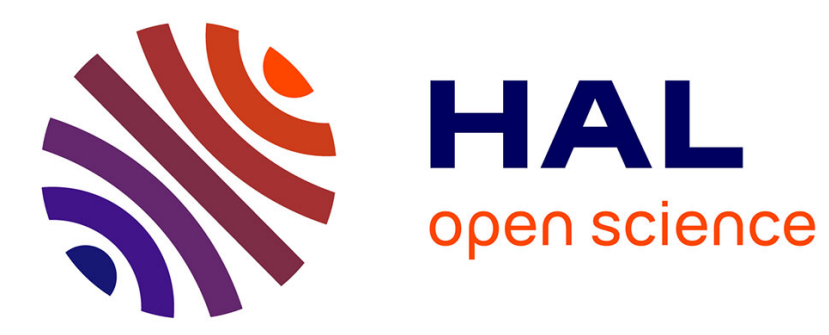

\title{
State estimation for a fish population via a nonlinear observer
}

Abderrahman Iggidr, Mohamed Oumoun, Jean-Claude Vivalda

\section{To cite this version:}

Abderrahman Iggidr, Mohamed Oumoun, Jean-Claude Vivalda. State estimation for a fish population via a nonlinear observer. 2000 American Control Conference - ACC 2000 , Jun 2000, Chicago, Illinois, United States. pp.713-714, 10.1109/acc.2000.878994 . hal-01862866

\section{HAL Id: hal-01862866 https://hal.inria.fr/hal-01862866}

Submitted on 29 Aug 2018

HAL is a multi-disciplinary open access archive for the deposit and dissemination of scientific research documents, whether they are published or not. The documents may come from teaching and research institutions in France or abroad, or from public or private research centers.
L'archive ouverte pluridisciplinaire HAL, est destinée au dépôt et à la diffusion de documents scientifiques de niveau recherche, publiés ou non, émanant des établissements d'enseignement et de recherche français ou étrangers, des laboratoires publics ou privés. 


\title{
State estimation for a fish population via a nonlinear observer $^{1}$
}

\author{
A. Iggidr ${ }^{2}$ M. Oumoun J.C. Vivalda \\ CONGE Project \\ INRIA Lorraine \& CNRS UPRESA 7035 \\ I.S.G.M.P. Bat. A, Ile du Saulcy \\ 57045 Metz cedex 01, FRANCE. \\ e-mail: \{iggidr,oumoun, vivalda\}@loria.fr
}

\begin{abstract}
This paper focuses on the construction of an exponential observer for an age-structured model of an exploited fish population in order to get an estimation of the number of fishes by age class. The considered model is nonlinear and involves a stock-recruitment function which is not well known. The observer that we construct is independent of this function.
\end{abstract}

Key words: discrete-time systems, estimation, nonlinear control systems, observer, population dynamics.

\section{Introduction}

We consider a population of exploited fish which is structured in $n$ age classes $(n \geq 2)$; under some assumptions on the population, we can represent the dynamics of the population by the following system of difference equations:

$$
\left\{\begin{aligned}
x_{1}(t+1)= & f\left(\sum_{i=1}^{n} b_{i} x_{i}(t)\right) \\
x_{2}(t+1)= & x_{1}(t) \exp \left(-M_{1}-q_{1} E(t)\right) \\
\vdots & \vdots \\
x_{n}(t+1)= & x_{n-1}(t) \exp \left(-M_{n-1}-q_{n-1} E(t)\right)
\end{aligned}\right.
$$

where $f: \mathbb{R}_{+} \rightarrow \mathbb{R}_{+}$is the stock-recruitment function. It is a continuous map such that $f(0)=0$ and

- $b_{i}$ is the number of individuals produced by individuals of the $i^{\text {th }}$ age class;

- $M_{i}$ is the natural mortality of the individuals of the $i^{\text {th }}$ age class;

- $q_{i}$ is the catchability of the individuals of the $i^{\text {th }}$ age class;

\footnotetext{
${ }^{1}$ travail réalisé dans le cadre du groupement de recherche COREV.

${ }^{2}$ Corresponding author
}

- $E(t)$ is the fishing effort at time $t$ and is regarded as an input.

Several authors have proposed different kind of functions $f$ (see $[1,4,6,7]$. The most quoted mathematical expressions of the nonlinear recruitment function $f$ are ( $\beta$ being a positive parameter):

$$
\begin{array}{ll}
\text { Beverton and Holt } & f(x)=\frac{x}{1+\beta x} ; \\
\text { Ricker } & f(x)=e^{-\beta x} ; \\
\text { Powerfunction } & f(x)=x^{-\beta} ; \\
\text { Shepherd } & f(x)=\frac{x}{1+\beta x^{c}},(c>0) .
\end{array}
$$

Our aim is to construct an observer, that is to say, an auxiliary system of difference equations whose state $z(t)$ gives an estimate of the state $x(t)$ of system (1). More precisely we shall have $\lim _{t \rightarrow+\infty}(z(t)-x(t))=0$ with an exponential rate of convergence, i.e, there exists $\alpha<1$ such that, for all $t \in \mathbb{N}$ and for all initial conditions $(x(0), z(0))$, one has

$$
|z(t)-x(t)| \leq \alpha^{t}|z(0)-x(0)| .
$$

We wish to do this job without using a precise expression of the function $f$ : we shall use only some minimal assumption on this function. One can notice that although the theory of observer design for linear systems is a well developped field, its analogous part for nonlinear systems is an intriguing subject, and is still receiving considerable attention by many researchers. The design of state observers for discret-time systems has been studied in many articles. One can cite, for example, $[2,3]$ where the problem has been addressed for general systems but the given observers are only local and here we rae interested in the construction of a global observer. In [5], the observer design is done in the context of solving simultaneous nonlinear equations by using Newton's algorithm. Here we give a new procedure that simplifies the observer design for the considered system. 


\section{Design of an exponential observer}

System (1) can be rewritten with standard control notations:

$$
\left\{\begin{aligned}
x(t+1) & =F(x(t), u(t)) ; \\
y(t) & =h(x(t), u(t)) ;
\end{aligned}\right.
$$

where $x(t) \in \Omega=\mathbb{R}_{+}^{n}$, is the state of the system, $u(t)=$ $E(t) \in \mathbb{R}_{+}$, is the control (here it is the fishing effort) and $y(t) \in \mathbb{R}_{+}$, is the measurable output of the system.

We assume that we can measure the quantity of catched fishes which is expressed by :

$$
y(t)=\sum_{i=1}^{n-1} x_{i}(t) e^{-M_{i}}\left(1-\exp \left(-q_{i} E(t)\right)\right) .
$$

We suppose that the fishing effort is subject to the constraints:

$$
0<E_{\mathrm{m}} \leq E(t) \leq E_{\mathrm{M}}
$$

(this assumption is reasonable because if we don't catch any fish, we can't get any information on the population).

Below, we expose a system that we claim to be an observer for (1), for simplicity of exposition, the construction is made in the 3 -dimensional case (3 age classes).

$$
\left\{\begin{array}{l}
z_{1}(t+1)=\frac{y(t+1)-\left(e^{-M_{2}}-v_{2}(t+1)\right) v_{1}(t) z_{1}(t)}{e^{-M_{1}}-v_{1}(t+1)} \\
z_{2}(t+1)=v_{1}(t) z_{1}(t) \\
z_{3}(t+1)=v_{2}(t) z_{2}(t)
\end{array}\right.
$$

where we put $v_{i}(t)=\exp \left(-M_{i}-q_{i} E(t)\right)$.

Proposition 2.1 Assume that $E_{\mathrm{m}} \geq \ln 2 / q_{1}$, then system (3) is an observer for system (1).

Proof. Letting $e(t)=x(t)-z(t)$, we have:

$$
\left\{\begin{aligned}
e_{1}(t+1) & =x_{1}(t+1)-z_{1}(t+1) \\
& =-\frac{e^{-M_{2}}-v_{2}(t+1)}{e^{-M_{1}}-v_{1}(t+1)} v_{1}(t) e_{1}(t) \\
e_{2}(t+1) & =v_{1}(t) e_{1}(t) \\
e_{3}(t+1) & =v_{2}(t) e_{2}(t)
\end{aligned}\right.
$$

thus:

$$
\begin{aligned}
\left|e_{1}(t+1)\right| & =\frac{1-e^{-q_{2} E(t+1)}}{1-e^{-q_{1} E(t+1)}} v_{1}(t)\left|e_{1}(t)\right| \\
& \leq \frac{1-e^{-q_{2} E_{\mathrm{M}}}}{1-e^{-q_{1} E_{\mathrm{m}}}} e^{-M_{2}} e^{-M_{1}-q_{1} E_{\mathrm{m}}}\left|e_{1}(t)\right|
\end{aligned}
$$

now since $E_{\mathrm{m}} \geq \ln 2 / q_{1}, e^{-q_{1} E_{\mathrm{m}}} /\left(1-e^{-q_{1} E_{\mathrm{m}}}\right) \leq 1$ which implies

$$
\left|e_{1}(t+1)\right| \leq \alpha\left|e_{1}(t)\right|
$$

where $\alpha=e^{-M_{2}}\left(1-e^{-q_{2} E_{\mathrm{M}}}\right)<1$. This proves the exponential convergence of $e_{1}(t)$ to zero and from (4), it is clear that the same is true for $e_{2}(t)$ and $e_{3}(t)$.

Remark. There is an alternative proof which uses the following candidate Lyapunov function $V(e)=e^{T} P e$, with:

$$
P=\left(\begin{array}{ccc}
\frac{3}{1-\alpha^{2}} & 0 & 0 \\
0 & 2 & 0 \\
0 & 0 & 1
\end{array}\right)
$$

Where, $\alpha=e^{-M_{2}}\left(1-e^{-q_{2} E_{\mathrm{M}}}\right)<1$.

\section{References}

[1] R.J.H. Beverton and S.J. Holt. On the dynamics of exploited fish populations. Chapman \& Hall, New York. First edition 1957.

[2] G. Ciccarella, M. Dalla Mora and A. Germani. Observers for discrete-time nonlinear systems Systems Control Lett., 205 (1993), 373-382.

[3] Y. Song and J.W. Grizzle. The extended Kalman filter as a local asymptotic observer for discrete time nonlinear systems. J. of Mathematical Systems, Estimation, and Control, 5 , No.1 (1995), 59-78.

[4] P. Magal and D. Pelletier A fixed point theorem with application to a model of population dynamics. $J$. Difference Equ. Appl., 3, No.1 (1997), 65-87.

[5] J.W. Grizzle and P.E. Moraal. Newton, observers and nonlinear discrete-time nonlinear control Proc. 29th CDC, (1990), 760-769.

[6] W. E. Ricker. Stock and recruitment. J. Fish. Res. Board Can., 11 (1954), 559-623.

[7] J. G. Shepherd. A family of general production curves for exploited populations. Mathematical Bioscinces, 59 (1982), 77-93. 